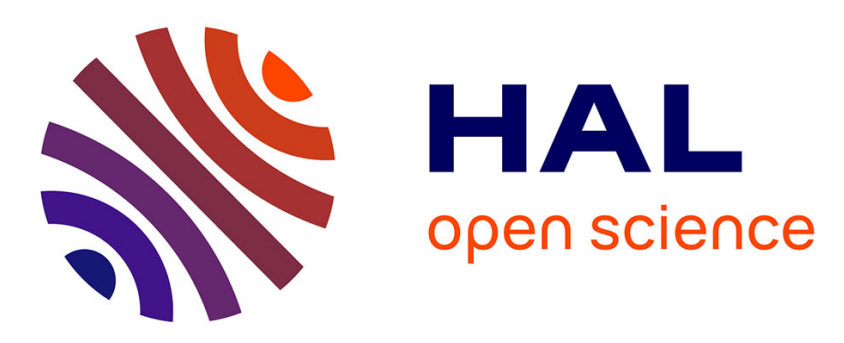

\title{
Standard addition method for the determination of pharmaceutical residues in drinking water by SPE-LC-MS/MS
}

Nicolas Cimetiere, Isabelle Soutrel, Marguerite Lemasle, Alain Laplanche, André Crocq

\section{To cite this version:}

Nicolas Cimetiere, Isabelle Soutrel, Marguerite Lemasle, Alain Laplanche, André Crocq. Standard addition method for the determination of pharmaceutical residues in drinking water by SPE-LCMS/MS. Environmental Technology, 2013, pp.Published online. 10.1080/09593330.2013.800563 . hal-00870208

\section{HAL Id: hal-00870208 \\ https://hal.science/hal-00870208}

Submitted on 6 Oct 2013

HAL is a multi-disciplinary open access archive for the deposit and dissemination of scientific research documents, whether they are published or not. The documents may come from teaching and research institutions in France or abroad, or from public or private research centers.
L'archive ouverte pluridisciplinaire HAL, est destinée au dépôt et à la diffusion de documents scientifiques de niveau recherche, publiés ou non, émanant des établissements d'enseignement et de recherche français ou étrangers, des laboratoires publics ou privés. 
1 STANDARD ADDITION METHOD FOR THE DETERMINATION OF

2 PHARMACEUTICAL RESIDUES IN DRINKING WATER BY SPE-

$6 \quad{ }^{*}$ Nicolas Cimetiere $^{\mathrm{ab}}$, Isabelle Soutrel ${ }^{\mathrm{ab}}$, Marguerite Lemasle ${ }^{\mathrm{ab}}$, Alain Laplanche ${ }^{\mathrm{ab}}$, and André $\mathrm{Crocq}^{\mathrm{c}}$

${ }^{a}$ Ecole Nationale de Chimie de Rennes, CNRS, UMR 6226,

$9{ }^{b}$ Université Européenne de Bretagne

$10{ }^{c}$ Veolia Eau, Direction Technique Région Ouest, 8 Allée Rodolphe Bobierre, 35020 Rennes

11 Cedex 9, France

12

13

14 *Corresponding author phone: +332232380 15; fax: +332232381 20;

15 e-mail address: nicolas.cimetiere @ ensc-rennes.fr

16 17 


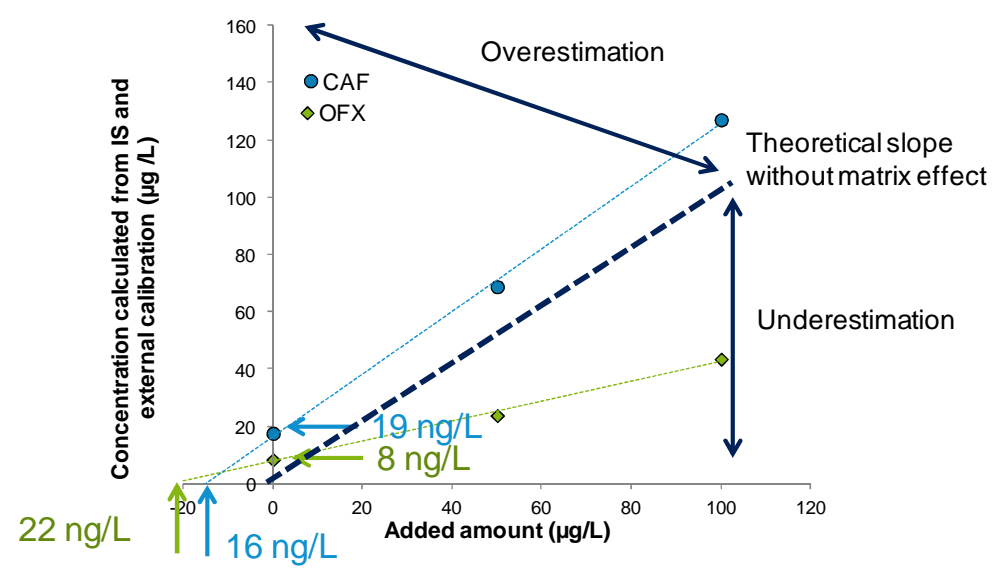

\section{Abstract}

22 The study of the occurrence and fate of pharmaceutical compounds in drinking or waste

23 water processes has become very popular in recent years. LC-MS/MS is a powerful 24 analytical tool often used to determine pharmaceutical residues at trace level in water. 25 However, many steps may disrupt the analytical procedure and bias the results. A list of 27 26 environmentally relevant molecules, including various therapeutic classes and 27 (cardiovascular, veterinary and human antibiotics, neuroleptics, non-steroidal anti28 inflammatory drugs, hormones and other miscellaneous pharmaceutical compounds) was 29 selected. In this work, a method was developed using Ultra Performance Liquid 30 Chromatography coupled to tandem Mass Spectrometry (UPLC-MS/MS) and solid phase 31 extraction (SPE) to determine the concentration of the 27 targeted pharmaceutical 32 compounds at the nanogram per liter level. The matrix effect was evaluated from water 33 sampled at different treatment stages. Conventional methods with external calibration and 34 internal standard correction were compared to the standard addition method. An accurate 35 determination of pharmaceutical compounds in drinking water was obtained by the 
standard addition method associated with UPLC-MS/MS. The developed method was used to evaluate the occurrence and fate of pharmaceutical compounds in some drinking water treatment plants (DWTPs) in the west of France.

Key words: Pharmaceutical compounds; Multiresidue analysis; Ultra Pressure Liquid Chromatography tandem Mass Spectrometry (LC-MS/MS); drinking water; standard addition method.

Human and veterinary uses of pharmaceutical compounds lead to the releasing of bioactive compounds into the aquatic environment. Metabolization rates depend on the nature of the drugs and may range from $1-96 \%$ [1]. Non-metabolized drugs are thus excreted in urine as free or conjugated forms $[2,3]$, and collect in the waste water network. Pharmaceutical compounds are not completely removed during waste water treatment [4-7]. The efficiency of the process depends on the operating conditions and the nature of the molecule [6]. For example, conventional treatment with activated sludge effectively eliminates ibuprofen, and benzafibrate while diclofenac, carbamazepine and sulfamethoxazole are scarcely removed [8]. Some pilot scale studies have been carried out using a membrane bioreactor in an attempt to improve the outcome; these processes were found to be more efficient than activated sludge reactors at removing pharmaceutical compounds $[8,9]$. The disinfection of treated waste water can also improve the elimination rate of pharmaceutical compounds [10]. An indirect way of introducing these compounds into the environment is via agricultural activities. Sludge from waste water treatment plants may be spread on fields as 
59 a fertilizer and the pharmaceutical compounds which can be immobilized in this sludge

60

61 may then contaminate the soil [11]. The veterinary use of drugs can lead to a direct environmental contamination by the discharge of untreated effluent from intensive animal farming. Direct soil contamination can occur by the excretion of urine and feces by farm animals onto fields [12]. Rainfall and soil leaching may then transport pharmaceutical compounds from the soil to the aquatic compartment [13]. Intensive livestock farming is one of the main economic sectors of Brittany area (north-west France). Moreover, a large proportion of the population uses a non-collective waste water treatment to clean household effluent, so drinking water treatment specialists are beginning to be concerned about the potential contamination of water resources by pharmaceutical compounds. Some recent study shows that

Recently the French Agency for Food Health Safety (AFSSA) determined, the main relevant molecules to examine in drinking water from the total amount consumed and their properties in the aqueous phase [14]. Based on this work, a wide measurement campaign was carried out by the French Agency for Environmental and Occupational Health Safety (ANSES) [15]. From the 150 molecules included in the ANSES study, only 20 were found at concentrations above the the limit of quantification (LOQ) and 11 between the limit of detection (LOD) and the LOQ. Only these molecules were selected for the present work. Accurate trace determination of emerging contaminants in the environment is an important analytical challenge. The first obstacle is associated with the gap between environmental concentrations and the quantification limits of analytical systems. Pharmaceutical compounds concentrations range from LOQ of $2000 \mathrm{ng} \mathrm{L}^{-1}$ to LOQ of $200 \mathrm{ng} \mathrm{L}^{-1}$ in surface water and drinking water, respectively [16-19] while the LOQ of conventional MS-MS 
82 apparatus (without a pre-concentration step), are typically in the $\mu \mathrm{g} \mathrm{L}^{-1}$ range. 83 Consequently, a concentration step is needed before analysis; solid phase extraction (SPE)

84 is the method of choice for the determination of emerging contaminants in water [20-22].

85 The second obstacle, resulting from the use of SPE, is the concomitant extraction of 86 interfering species and the target molecules. Polar organic pollutants are commonly 87 determined by liquid chromatography with tandem mass spectrometry (LC-MS/MS). 88 However, interfering species may affect the analytical procedure at different stages: i) some 89 compounds may react with targeted molecules during the sampling and storage periods, ii) 90 organic or inorganic solutes may affect the yield of SPE extraction, iii) natural organic 91 matter may coeluate with targeted compounds which leads to a signal disrupting with 92 under/overestimation or false positive samples [23]. The study presented here deals with 93 the development of the method including an evaluation of the matrix effect. Accurate 94 determination of pharmaceutical compounds in drinking water was performed by the standard addition method associated with ultra pressure liquid chromatography and tandem mass spectrometry. The method was used to evaluate the occurrence and fate of pharmaceutical compounds in some drinking water treatment plants (DWTP) in the west of France.

\section{Materials and methods}

\subsection{Stock solution and standard preparation.}

Stock solutions of individual pharmaceutical compounds were prepared by diluting reagentgrade chemicals (Sigma Aldrich) in methanol (Fisher). Ultra pure water (UPW) was provided by an ElgaPureLab System (18.2 M $\Omega . c m)$. Chromatographic solvents (MeCN; 
MeCN with $0.1 \%$ formic acid) were purchased from JT Baker (LC-MS grade) and were

105

106

107

108

109

110

111

112

113 used in association with UPW or UPW with $0.1 \%$ formic acid. A standard mix solution (5 and $10 \mathrm{mg} \mathrm{L}^{-1}$ in $\mathrm{MeOH}$ ) was prepared from individual stock solutions including all the targeted molecules except amoxicillin, caffeine, oxazepam and internal standards. The solution was then divided into a series of vial and stored at $-20^{\circ} \mathrm{C}$ in the dark. The vial containing the standard mix was placed at room temperature before use and the unused amount was discarded. The standard mix was used to prepare both injections standard for the external calibration and spiked solutions for the standard addition method. Amoxicillin, caffeine, and oxazepam stock solution were prepared in UPW, MeOH and $\mathrm{MeCN}$, respectively. Calibration curves were plotted using eight-level standard solutions $(1,2,5$, 10, 25, 50, 100, $200 \mu \mathrm{g} \mathrm{L} \mathrm{L}^{-1}$ and up to $2000 \mu \mathrm{g} \mathrm{\textrm {L } ^ { - 1 }}$ for caffeine). The chromatographic sequence consisted of the injection of standards and samples as follows: calibration curve first samples analysis - calibration curve - second samples analysis - calibration curve. In addition a middle-range standard solution was injected every 10 injections in order to verify the absence of significant signal deviation.

\subsection{Sample preparation}

On arrival at the laboratory, water samples stored in 2-L amber glass bottles were filtered through a $0.45 \mu \mathrm{m}$ cellulose acetate membrane to remove suspended matter and colloids. Samples were then stored in the dark before preparation and analysis. All the analyses were carried out within a maximum storage period of 5 days. Solid phase extraction was performed by filtering $200 \mathrm{~mL}$ of sample into a $6 \mathrm{~mL}$ Oasis HLB cartridge $(6 \mathrm{cc}, 150 \mathrm{~mL}$, Waters). HLB cartridges were conditioned with $5 \mathrm{~mL}$ of $\mathrm{MeCN}$ and rinsed with $5 \mathrm{~mL}$ of UPW prior to the extraction step. Extraction was conducted by the filtering $200 \mathrm{~mL}$ of 
127 sample (acidified at $\mathrm{pH}=2$ with sulfuric acid or not) under reduced pressure at a flow rate

128 of approximately $3 \mathrm{~mL} \mathrm{~min}^{-1}$. The cartridge was cleaned with $5 \mathrm{~mL} \mathrm{UPW}$ or UPW acidified

129 at $\mathrm{pH}=2$ (depending on the extraction method used) and then eluted with $4 \mathrm{~mL}$ MeCN.

130 The extract was evaporated under nitrogen flow to obtain a final volume of $100 \mu \mathrm{L} .100 \mu \mathrm{L}$

131 of internal standard (caffeine- ${ }^{13} \mathrm{C}_{3}$ and ibuprofene- $\mathrm{d}_{3}, 100 \mu \mathrm{g} \mathrm{L}{ }^{-1}$ in MeCN/UPW 10/90)

132 was added prior to LC-MS/MS analysis.

\section{2.3. Liquid Chromatography Tandem Mass Spectrometry}

134 All samples were analyzed using LC/MS/MS equipped with an electrospray ionization 135 source (ESI). The analytical equipment consisted of an ultra pressure liquid 136 chromatography system (Acquity, Waters) equipped with a reversed phase UPLC column 137 from Waters (Acquity C18 BEH, $100 \mathrm{~mm}$ x $2.1 \mathrm{~mm} \mathrm{ID}, 1.7 \mu \mathrm{m}$ ) and thermostated at $45^{\circ} \mathrm{C}$.

138 The autosampler temperature was set at $4^{\circ} \mathrm{C}$, and the injection volume was $5 \mu \mathrm{L}$ in the full139 loop mode. The mass spectrometer (Quattro Premier; Micromass) general operating 140 conditions were : cone gas $\left(\mathrm{N}_{2}, 50 \mathrm{~L} \mathrm{~h}^{-1}, 120^{\circ} \mathrm{C}\right)$-desolvation gas $\left(\mathrm{N}_{2}, 750 \mathrm{~L} \mathrm{~h}^{-1}, 350^{\circ} \mathrm{C}\right)$;

141 collision gas $\left(\mathrm{Ar}, 0.1 \mathrm{~mL} \mathrm{~min}^{-1}\right)$; capillary voltage $(3000 \mathrm{~V})$. The advanced mass parameters 142 (cone and collision cell voltage) are further described in Table 1.

$143 \quad 3 . \quad$ Results and discussion

Infusion is the first step of method development by liquid chromatography tandem mass

146 spectrometry. It consists of a direct analysis of a pure diluted solution without separation in 147 order to record the mass spectrum of each selected compound and to determine the MRM 148 transitions. During this step the MS parameters such as cone voltage, and collision cell 149 energy were optimized for each compound in order to achieve the maximum sensitivity. 
150 Table 1 shows the results obtained for the 29 molecules studied here; 3 internal and

151 recovery standards are also included. ESI is soft ionization technique which allows the

152 selection of a pseudo-molecular ion as the parent ion for MRM transitions; ESI was used in

153 both the negative and positive mode. The positive mode was selected for most of the

154 molecules while 9 analytes were ionized under the negative mode. The pseudo-molecular 155 ion $\left([\mathrm{M}+\mathrm{H}]^{+}\right.$or $\left.[\mathrm{M}-\mathrm{H}]^{-}\right)$was selected as the parent ion. When possible, simple fragment 156 loss, such as water or carbon dioxide, was selected for the quantification or confirmation

157 transition (parent ion $\rightarrow$ daughter ion for the quantification and second daughter ion for 158 confirmation). Only 1 transition was found for ibuprofen and ibubuprofen- $\mathrm{d}_{3}$.

\subsection{Chromatographic conditions and calibration}

160 UPLC with a BEH C18 column was performed with a gradient of ultra-pure water /

161 acetonitrile at $400 \mu \mathrm{L} \mathrm{min}{ }^{-1}$. The effect of formic acid addition on the chromatographic

162 separation was also evaluated. The starting eluent composition consisted of $19 \%$

163 acetonitrile for 1 minute, which was then linearly increased to reach $95.5 \%$ at 7.5 minutes.

164 A final eluent containing $95.5 \%$ acetonitrile for 2 minutes was used to clean the column 165 and prevent any parasite peaks. In order to obtain an acceptable detection of all the 166 molecules, 2 chromatographic conditions, with and without formic acid addition, to 167 promote ionization, were needed (Figure 1). Separation was achieved in 6 minutes with a 168 complete chromatographic run of 12 minutes. Caffeine- $-{ }^{13} \mathrm{C}_{3}\left(\mathrm{CAF}-{ }^{13} \mathrm{C}_{3}\right)$ and ibuprofen- $\mathrm{d}_{3}$ 169 (IBU- $\left.\mathrm{d}_{3}\right)$ were used as the internal standard for quantification under the positive and 170 negative ionization modes, respectively. Moreover, a recovery standard (ketoprofen- $\mathrm{d}_{3}$ ) was 171 added prior to the solid phase extraction; no correction relative to ketoprofen-d 3 was made 
and its use was only indicative. External calibration curves were used for the determination

173 of relative response factors (RRF) for each analyte according to the following equations:

$\mathrm{RRF}($ positive $)=\frac{\text { Analyte slope }}{\mathrm{CAF}-{ }^{13} \mathrm{C}_{3} \text { slope }} \quad$ (negative) $=\frac{\text { Analyte slope }}{\mathrm{IBU}-\mathrm{d}_{3} \text { slope }}$

\subsection{Linearity and quantification limits}

Recovery rates (RR), linearity and quantification limits were determined at environmentally relevant concentrations; the results are summarized in Table 1. Because those obtained with UPW and surface water samples cannot be easily compared, the evaluation of the basic parameters of the validation method was carried out without organic interfering species (UPW or Evian water). Linearity was validated between $5-200 \mu \mathrm{g} \mathrm{L}^{-1}$ in the vial (injected volume $=5 \mu \mathrm{L}$ ) which corresponds to $5-200 \mathrm{ng} \mathrm{L}^{-1}$ in the starting sample if the $\mathrm{RR}$ is considered equal to $100 \%$. External calibration curves ( 8 levels +1 blank) were also used to determine the standard deviation on the instrumental method; the SD presented here does not include the deviation on the SPE step. The results show that acceptable relative standard deviations lower than $10 \%$ were obtained for most of the pharmaceutical compounds. However poor-quality results were obtained for hormones with a relative standard deviation ranging from 40 to $60 \%$.

The evaluation of instrumental detection $(\mathrm{S} / \mathrm{N}=3)$ and quantification limits $(\mathrm{S} / \mathrm{N}=10)$ (IDL and IQL) was performed by the injection of 10 blank samples (Evian water). From the 29 targeted compounds, IQL lower than $4 \mu \mathrm{g} \mathrm{L}^{-1}$ were obtained for 27 of them, demonstrating that determination in the nanogram per liter range requires a concentration factor of up to 1000. Higher IQL values were obtained for ethinylestradiol and salicylic acid (8 and $24 \mu \mathrm{g} \mathrm{L}^{-1}$, respectively). It should be underlined that the evaluation of the limit 
193 of quantification (LOQ) by this method (apparatus LOQ without the SPE step and in the

194 absence of interfering compounds) is not directly transposable for the determination of

195 pharmaceutical residues in surface water. Nevertheless, this quick approach demonstrates

196 that our method enables pharmaceuticals in surface and drinking water to be determined at

197 an environmentally relevant concentration.

\subsection{SPE extraction}

199 Solid phase extractions were performed with Oasis HLB cartridges by filtering $200 \mathrm{~mL}$ of $200 \quad 0.45 \mu \mathrm{m}$ pre-filtered sample in order to obtain a concentration factor of 1000 . Because the 201 selected molecules can be assumed to be weakly basic or weakly acid compounds, the 202 effect of sample the acidification on the extraction yield was evaluated in UPW. Standard 203 solutions each containing $100 \mathrm{ng} \mathrm{L}^{-1}$ of analyte were filtered onto an HLB cartridge as 204 previously described. Recovery rates were determined using the internal standards caffeine$205{ }^{13} \mathrm{C}_{3}$ and ibuprofen- $\mathrm{d}_{3}$ for the analysis under ESI+ and ESI-, respectively (Figure 2).

206 The results of the extraction experiments are summarized in Table 1. Acetaminophen, 207 caffeine, carbamazepine, and oxazepam were almost quantitatively (80-120\%) recovered in 208 conditions all investigated. These analytes are assumed to be neutral drugs, which explains 209 their high recovery yields under acidic and neutral extractions. In spite of a pKa value of 2104.16 , a similar result was obtained for losartan. Amphoteric drugs such as danofloxacin and 211 ofloxacin exhibited higher recovery yields under acidic extraction than under neutral 212 conditions. Thus, for these compounds, the SPE is controlled by the carboxylic function 213 and the amino group does not affect the extraction yield. The opposite effect was observed 214 for amoxicillin where no acceptable recovery yields were obtained under acidic or neutral 215 conditions. In this case, the controlling group should be the amino acid function and 
extraction under basic conditions could increase the recovery yield. Extraction under acidic conditions was selected for most of the carboxylic acids, for example ibuprofen, ketoprofen and salicylic acid. In contrast to acidic drugs, basic drugs containing an amino group (i.e. atenolol, naftidrofuryl and lincomycin) had comparatively higher recoveries under neutral conditions due to the formation of ammonium derivatives at low $\mathrm{pH}$ values. Except for amoxicillin, the combination of both acidic and neutral extractions provided acceptable recovery rates for all the analytes. However the recovery rates determined in UPW experiments could be dramatically affected by the presence of interfering species (i.e. 224 natural organic matter).

\subsection{Evaluation of the matrix effect}

The presence of organic or inorganic substances could lead to an analytical bias. Natural Organic Matter (NOM) is a complex mixture of polyfunctional macromolecules [24] which may disturb the SPE step, or MS ionization. From the various effects attributable to the presence of NOM some phenomena can be described such as competitive adsorption on the HLB phase [25], the formation of NOM-analyte complexes [26] and the modification of the analyte ionization efficiency in the MS source [27]. Although the presence of NOM is frequently associated with an underestimation of the targeted analytes (decreasing the extraction yield and/or the ionization efficiency), the opposite effect may also occur,

234 despite not being well documented.

235 In order to evaluate the effect of NOM, the recovery rates obtained in pure water were 236 compared with those obtained in surface water. Four surface waters (used to supply 237 drinking water treatment plants) were spiked with stock solutions of pharmaceutical 238 compounds to obtain a concentration of $100 \mathrm{ng} \mathrm{L}^{-1}$ of each targeted analyte. Because 
surface water may initially contain some pharmaceutical residues, unspiked samples were

240 also analyzed to determine the signal contribution due to the presence of analyte in surface

241 water; signal was then corrected to be specific to the added amount of analyte. Figure 3

242 shows the comparison between the recovery rates obtained in pure water and those obtained

243 in raw water (surface water) from the drinking water treatment plant A and B (DWTPA-

244 RW ; DWTPB-RW). These results demonstrate that the determination of pharmaceutical

245 compounds at trace level is very influenced by the water quality. For some compounds,

246 such as tylosin, atenolol, losartan, ibuprofen and amoxicillin, no significant matrix effect

247 was observed. The recovery rate determined for amoxicillin in surface water was quite

248 similar to that observed in pure water. However, due to its very low value, a possible matrix

249 effect may be masked. The absence of a detectable matrix effect on ibuprofen can be

250 explained by the fact that this compound was quantified relative to ibuprofen- $\mathrm{d}_{3}$. Figure 3

251 shows a significant underestimation of diclofenac and $\beta$-estradiol in surface water. In

252 contrast, many compounds such as carbamazepine and epoxy-carbamazepine were

253 overestimated. The recovery rate observed for oxazepam in pure water (105\%) was not

254 significantly different from that observed in DWTPA-RW (104\%) but a significant

255 overestimation was observed in DWTPB-RW (145\%). In the case of ethinylestradiol, 256 recovery rates in pure water and DWTPA-RW (108 and $89 \%$, respectively) were quite 257 similar whereas a significant underestimation was measured in DWTPB-RW (59 \%). 258 Clearly, the recovery rates determined with pure water are not transposable to surface 259 water. The recovery rates obtained with surface water differ depending on the nature of the 260 NOM. Therefore, a classical approach with external calibration and internal/external 
261 standard correction is not sufficiently accurate for the multi-residue analyses of 262 pharmaceutical compounds at trace level in water.

264 The standard addition method (SAM) is very efficient for correcting the matrix effect and providing an overall evaluation of this effect on both the SPE step and MS ionization. Moreover, it can be used even if the molecules were not initially present in water. All samples were spiked with stock solutions containing the 29 targeted pharmaceuticals (not spiked; 50 and $100 \mathrm{ng} \mathrm{L}^{-1}$ ). The conventional quantification method (external calibration 269 with internal standard correction) was compared with SAM results according to the 270 following equations:

conventional method: $[$ Analyte $]=\frac{\text { Analyte Area }}{\text { IS Area }} \times \frac{[\mathrm{IS}]}{\mathrm{RRF}}$ with $[\mathrm{IS}]=100 \mu \mathrm{g} \mathrm{L}^{-1}$

$$
\text { SAM method: }[\text { Analyte }]=\frac{\text { Measured signal in unspiked sample }}{\text { slope of the standard addition calibration curve }}
$$

271 Figure 4.a shows an example of matrix effect evaluation for some molecules not detected in 272 the raw water of DWTP A. In the absence of a matrix effect, a theoretical slope equal to 1 273 should be obtained; in the present case (DWTP A-RW), some compounds such as estrone 274 and sulfadimerazine were weakly affected by water quality and interfering species. 275 Conversely, the low recovery rate obtained for diclofenac could be attributed to a decrease 276 in the extraction yield and/or signal suppression caused by a modification of ionization in 277 the ESI source. The inverse effect was observed for naftidrofuryl, for which conventional quantification leads to an overestimation. Because no signal attributable to naftidrofuryl was observed in the non-spiked sample, the overestimation could not be due to the co- 
elution of a false-positive compound, but it could be caused by an ion enhancement effect.

281 This type of matrix effect has previously been reported in the literature [23] with similar compounds (basic drugs) in surface water. Moreover, Dams et al. [28] underlined that ESI was especially susceptible compared to APCI. The same approach was adopted with compounds initially observed in the non-spiked sample (Figure 4.b). In the case of caffeine, similar results were obtained with the conventional method $\left(19 \pm 3 \mathrm{ng} \mathrm{L}^{-1}\right)$ and SAM $(16 \pm$ $\left.3 \mathrm{ng} \mathrm{L}^{-1}\right)$. However, the quantification of ofloxacin by the conventional method $\left(8 \pm 2 \mathrm{ng} \mathrm{\textrm {L } ^ { - }}\right.$

${ }^{1}$ ) led to a significant underestimation (SAM: $22 \pm 3 \mathrm{ng} \mathrm{L}^{-1}$ ) of its concentration in drinking water.

289 The standard addition method was used to determine the concentration of pharmaceuticals 290 at different treatment stages from raw water to drinking water in four drinking water 291 treatment plants (DWTPs). The matrix effect was evaluated on a total of 16 samples. The 292 slopes of the curves, obtained with the 29 targeted compounds in the different samples 293 (example given in Figure 4), are summarized as a box plot (Figure 5.). These results underline that the chromatographic method proposed here fails to determine the 29 targeted compounds accurately. Recovery rates obtained for amoxicillin were lower than $3 \%$, which could be explained by the extraction step (SPE yield lower than $7 \%$ in pure water).

297 Moreover, in some cases amoxicillin was not detected in the spiked samples (50 and $100 \mathrm{ng}$ $298 \mathrm{~L}^{-1}$ ), so a competitive effect on the adsorption step and/or signal suppression could be 299 suggested in addition to poor SPE efficiency. Not only was salicylic acid dramatically 300 affected by the matrix effect, but antagonistic effects (signal suppression and enhancement) 301 were also observed with similar water qualities: large signal suppression was observed in 302 the raw water of DWTP A while signal enhancement occurred after the sand filtration step 
of the same DWTP. A review of the chromatographic data also reveals an abnormally large area associated with salicylic acid. In some cases, the calculated concentrations with both

305 the conventional and standard addition methods reach the milligram per liter range, so a 306 cross-talk effect could be suggested. As smaller deviations between the conventional 307 method and SAM were observed for compounds which were quantified relative to their 308 analogous IS (ibuprofen, caffeine), the results obtained here demonstrate that the correction 309 of the matrix effect with internal standards cannot easily be transposed to other compounds.

310 In spite of the efficiency of the SAM to correct the matrix effect, amoxicillin and salicylic 311 acid were removed from the quantifiable list of compounds; thus only the 27 of the 29 312 pharmaceutical compounds initially targeted were accurately quantified by the method 313 proposed here.

\section{$314 \quad$ 3.7. Application to drinking water analysis}

315 Concentrations of pharmaceutical compounds in the samples from DWTP were calculated 316 from Equation 3. The results obtained during the sampling campaign show that only 13 317 molecules were observed at concentrations above the LOD at least once. Figure 6 318 summarizes the occurrence and fate of the detected compounds in the four sampled 319 DWTPs. Concentrations observed ranged from the LOQ to $95 \mathrm{ng} \mathrm{L}^{-1}$ (hydroxy-ibuprofen in 320 DWTP D). From the 13 detected molecules, only 3 pharmaceutical compounds were 321 quantified in all samples (caffeine, ofloxacin, hydroxy-ibuprofen). 9 molecules were 322 detected with concentrations lower than the LOQ and 3 of these were only observed in raw 323 water (losartan, epoxy-carbamazepine and ketoprofen). Erythromycin, tylosin, 324 progesterone, hydrochlorothiazide and ibuprofen were detected (<LOQ) at different stage 325 of the water treatment. Finally 6 targeted compounds were never detected during the 
sampling campaign (lincomycin, diclofenac, estrone, pravastatin, atenolol and 327 doxycycline). It should be underlined that the SAM approach identified significant signal 328 inhibition of danofloxacin and ofloxacin in the raw water of DWTP B and in the 329 chlorinated water of DWTP A. Since the spiking of danofloxacin and ofloxacin does not 330 lead to a significant increase in peak area associated with these compounds, their 331 quantification was not possible. Nevertheless, ofloxacin and danofloxacin were accurately 332 determined after sand filtration at a concentration ranging from $5-10 \mathrm{ng} \mathrm{L}^{-1}$, so it could be 333 suggested that they were initially present in the raw water. This particular case reinforces 334 the efficiency of the SAM approach for identifying matrix effects and facilitating the 335 interpretation of results. Only the quantified compounds were considered when examining 336 the effect of the water treatment process on the removal of pharmaceuticals (Figure 6). 337 From the results obtained, 3 classes of pharmaceuticals can be defined. Several compounds, 338 such as caffeine, trimethazine and oxazepam were partially removed during the treatment 339 process. The clarification step (coagulation-flocculation-sand filtration) seemed to be most 340 efficient for eliminating pharmaceutical compounds. In fact, acetaminophen, 341 carbamazepine, amlodipine, sulfamethazine, $\beta$-estradiol and ethinylestradiol were 342 completely removed after this step. These data are consistent with the work of Vieno et al. 343 who demonstrated that coagulation of surface water with ferric sulfate could efficiently 344 remove some pharmaceutical residues [29]. A second class of compounds can be defined as 345 refractory pollutants; ofloxacin, danofloxacin and naftidrofuryl were not significantly 346 eliminated during drinking water production. The third group of molecules consists of 347 metabolites formed during water treatment; only hydroxy-ibuprofen in the present study. A 348 large increase in hydroxy-ibuprofen concentration was observed in all the DWTPs 
349 considered although ibuprofen was never observed at a concentration level above the LOQ.

350 The gulcuronide conjugate of ibuprofen is the main metabolite from ibuprofen metabolism

351 [3]. Cleavage of this conjugate could occur during water treatment releasing the free form

352 of ibuprofen, which could then be oxidized to produce hydroxy-ibuprofen. A similar

353 mechanism has previously been proposed by Ternes et al. to explain the formation of 354 estrone from the glucuronide conjugate of $\beta$-estradiol in a waste water treatment plant $355[[30]]$.

\section{4. Conclusion}

357 In this study, a multiresidue analysis of pharmaceuticals at trace level in surface and 358 drinking water involving a solid phase extraction followed by UPLC-MS/MS determination 359 was developed. Matrix effects were examined for 29 pharmaceuticals in 16 samples. Matrix 360 effects were severe, even with internal standard correction, so the standard addition method 361 was necessary for an accurate determination. The analytical method developed here was 362 then used to evaluate the occurrence and fate of drug residues in drinking water treatment 363 plants. Further studies will be conducted to confirm the effect of the water treatment 364 process on the elimination of pharmaceutical residues. 


\section{REFERENCES}

[1] M.S. de Graaff, N.M. Vieno, K. Kujawa-Roeleveld, G. Zeeman, H. Temmink, C.J.N. Buisman, Water Res. 45 (2011) 375.

[2] P. Adler, T. Steger-Hartmann, W. Kalbfus, Acta Hydrochim. Hydrobiol. 29 (2001) 227.

[3] N.M. Davies, Clin. Pharmacokinet. 34 (1998) 101.

[4] M.L. Janex-Habibi, A. Bruchet, T.A. Ternes, Tech., Sci., Methodes 11 (2004) 59.

[5] R.P. Schwarzenbach, B.I. Escher, K. Fenner, T.B. Hofstetter, C.A. Johnson, U. von Gunten, B. Wehrli, Science 313 (2006) 1072.

[6] C. Miège, J.M. Choubert, L. Ribeiro, M. Eusèbe, M. Coquery, Environ. Pollut. 157 (2009) 1721.

[7] T.A. Larsen, J. Lienert, A. Joss, H. Siegrist, J. Biotechnol. 113 (2004) 295.

[8] M. Clara, B. Strenn, O. Gans, E. Martinez, N. Kreuzinger, H. Kroiss, Water Res. 39 (2005) 4797.

[9] J. Radjenovic, M. Petrovic, D. Barceló, Anal. Bioanal. Chem. 387 (2007) 1365.

[10] G. Hey, A. Ledin, J.l.C. Jansen, H.R. Andersen, Environmental Technology 33 (2011) 1041.

[11] J. Radjenović, M. Petrović, D. Barceló, Water Res. 43 (2009) 831.

[12] I.S. Ruhoy, C.G. Daughton, Environ. Int. 34 (2008) 1157.

[13] A. Karnjanapiboonwong, J. Suski, A. Shah, Q. Cai, A. Morse, T. Anderson, Water, Air, Soil Pollut. 216 (2011) 257.

[14] AFFSA, in, 2008.

[15] ANSES, in, 2011.

[16] H. Budzinski, A. Togola, Environ. risques \& santé 5 (2006) 248.

[17] M. Farré, I. Ferrer, A. Ginebreda, M. Figueras, L. Olivella, L. Tirapu, M. Vilanova, D. Barceló, J. Chromatogr., A 938 (2001) 187.

[18] P.E. Stackelberg, J. Gibs, E.T. Furlong, M.T. Meyer, S.D. Zaugg, R.L. Lippincott, Sci. Total Environ. 377 (2007) 255.

[19] O.A.H. Jones, N. Voulvoulis, J.N. Lester, Environmental Technology 22 (2001) 1383.

[20] B. Kasprzyk-Hordern, R.M. Dinsdale, A.J. Guwy, J. Chromatogr., A 1161 (2007) 132.

[21] M. Gros, M. Petrović, D. Barceló, Anal. Bioanal. Chem. 386 (2006) 941.

[22] C. Stavrakakis, R. Colin, V. Hequet, C. Faur, P. Le Cloirec, Environmental Technology 29 (2008) 279.

[23] J. Van De Steene, W. Lambert, J. Am. Soc. Mass Spectrom. 19 (2008) 713.

[24] E.M. Thurman, Organic Geochemistry of Natural Waters, Kluwer Academic, Boston, MA, USA., 1985.

[25] F. Tamtam, F. Mercier, J. Eurin, M. Chevreuil, B. Le Bot, Anal. Bioanal. Chem. 393 (2009) 1709.

[26] H.-C. Holten Lützhøft, W.H.J. Vaes, A.P. Freidig, B. Halling-Sørensen, J.L.M. Hermens, Environ. Sci. Technol. 34 (2000) 4989.

[27] R.J.C.A. Steen, A.C. Hogenboom, P.E.G. Leonards, R.A.L. Peerboom, W.P. Cofino, U.A.T. Brinkman, J. Chromatogr., A 857 (1999) 157. 
412 [29] N. Vieno, T. Tuhkanen, L. Kronberg, Environmental Technology 27 (2006) 183.

413 [30] T.A. Ternes, P. Kreckel, J. Mueller, Sci. Total Environ. 225 (1999) 91. 


\section{Table 1. Summary of the method development}

\begin{tabular}{|c|c|c|c|c|c|c|c|c|c|c|c|c|c|}
\hline \multirow{2}{*}{\multicolumn{2}{|c|}{ Therapeutic class }} & \multirow{2}{*}{ Molecule } & \multirow{2}{*}{$\underset{\text { (g/mol) }}{\text { MW }}$} & \multirow{2}{*}{$\begin{array}{c}\text { ESI } \\
(+/-) \\
\end{array}$} & \multicolumn{3}{|c|}{ MRM transitions $(\mathrm{m} / \mathrm{z})$} & \multirow{2}{*}{$r^{2}$} & \multirow{2}{*}{ SD } & \multirow{2}{*}{$\underset{\left(\mu \mathrm{g} \mathrm{L}^{-1}\right)}{\text { LOD }}$} & \multirow{2}{*}{$\begin{array}{c}\mathbf{L O Q} \\
\left(\mu \mathrm{g} \mathrm{L} \mathbf{L}^{-1}\right)\end{array}$} & \multirow[t]{2}{*}{ SPE } & \multirow[t]{2}{*}{ UPLC } \\
\hline & & & & & Parent ion. $\left(\mathrm{CV}^{\mathrm{a}}\right)$ & Quant. ion $\left(\mathbf{C E}^{\mathrm{b}}\right)$ & Conf. ion (CE) & & & & & & \\
\hline \multirow{6}{*}{\multicolumn{2}{|c|}{ 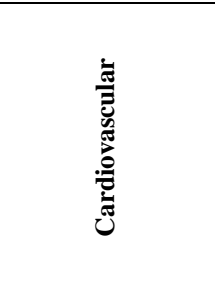 }} & Amlodipine (AML)* & $567.05^{*}$ & + & $409.6(18)$ & $238.1(11)$ & $292.2(13)$ & 0.994 & 0.109 & 0,3 & 1,0 & ${ }^{\mathrm{c}} \mathrm{A}$ & A \\
\hline & & Atenolol (ATE) & 266.34 & + & $267.0(34)$ & $145.0(26)$ & $74.0(23)$ & 0.986 & 0.118 & 0,2 & 1,0 & ${ }^{d} N$ & A \\
\hline & & Losartan (LOS)* & $461.00^{*}$ & + & $423.6(30)$ & $405.2(12)$ & $207.0(22)$ & 0.987 & 0.100 & 0,4 & 1,0 & ${ }^{\mathrm{e}} \mathrm{N}+\mathrm{A}$ & A \\
\hline & & Naftidrofuryl (NAF)* & 473.56 & + & $384.6(40)$ & $99.7(21)$ & $84.7(25)$ & 0.992 & 0.106 & 1,4 & 2,0 & $\mathrm{~N}$ & A \\
\hline & & Pravastatin (PRA)* & 446.51 & - & $423.2(34)$ & $100.6(23)$ & $321.1(16)$ & 0.988 & 0.119 & 0,1 & 1,0 & $\mathrm{~N}$ & $\mathrm{~N}$ \\
\hline & & Trimetazidine (TRI)* & 339.26 & + & $267.4(21)$ & $180.9(16)$ & $165.8(26)$ & 0.995 & 0.082 & 0,2 & 1,0 & $\mathrm{~N}$ & A \\
\hline \multirow{8}{*}{ 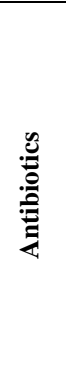 } & \multirow{4}{*}{ 葛 } & Amoxicillin (AMO) & 365.40 & + & $366.5(16)$ & $113.7(24)$ & $349.0(10)$ & 0.980 & 0,176 & 0,4 & 1,0 & A & A \\
\hline & & Doxycycline (DOX)* & 512.94 & + & $445.5(30)$ & $428.2(18)$ & $153.8(28)$ & 0.986 & 0,103 & 0,7 & 2,0 & A & A \\
\hline & & Erythromycin (ERY) * & $769.96^{*}$ & + & $734.2(28)$ & $158.0(30)$ & $576.2(19)$ & 0.987 & 0,123 & 0,0 & 1,0 & $\mathrm{~N}$ & A \\
\hline & & Ofloxacin (OFX) & 361.37 & + & $362.0(34)$ & $318.0(19)$ & $261.0(28)$ & 0.985 & 0,155 & 0,9 & 2,0 & A & A \\
\hline & \multirow{4}{*}{ 离 } & Danofloxacin (DANO) & 357.38 & + & $358.5(35)$ & $314.0(19)$ & $283.0(25)$ & 0.976 & 0,210 & 1,8 & 4,0 & A & A \\
\hline & & Lincomycin (LINCO)* & 461.01 & + & $407.6(40)$ & $125.9(28)$ & $359.3(18)$ & 0.984 & 0,125 & 0,0 & 1,0 & $\mathrm{~N}$ & A \\
\hline & & Sulfadimerazine (SFZ) & 278.33 & + & $279.4(29)$ & $185.9(16)$ & $91.7(26)$ & 0.979 & 0,133 & 0,3 & 1,0 & $\mathrm{~N}$ & A \\
\hline & & Tylosin (TYL) * & $1066.19^{*}$ & + & $917.0(60)$ & $174.0(37)$ & $773.0(29)$ & 0.994 & 0,088 & 0,3 & 1,0 & $\mathrm{~N}$ & A \\
\hline \multirow{3}{*}{\multicolumn{2}{|c|}{ Neuro. }} & Carbamazepine (CBZ) & 236.27 & + & $237.1(28)$ & $194.0(19)$ & $179.0(39)$ & 0.976 & 0.122 & 0,1 & 1,0 & $\mathrm{~N}+\mathrm{A}$ & A \\
\hline & & Epoxycarbamazepine (Ep-CBZ) & 252.27 & + & $253.3(28)$ & $179.9(28)$ & $236.0(12)$ & 0.988 & 0.111 & 0,3 & 1,0 & A & A \\
\hline & & Oxazepam (OZP) & 286.71 & + & $287.4(34)$ & $241.0(20)$ & $269.1(14)$ & 0.985 & 0.109 & 0,5 & 2,0 & $\mathrm{~N}+\mathrm{A}$ & A \\
\hline \multirow{5}{*}{\multicolumn{2}{|c|}{ NSAID }} & Diclofenac (DICLO) & 294,14 & + & $296,1(22)$ & $250,0(10)$ & $214,1(25)$ & 0.987 & 0.120 & 0,2 & 1,0 & $\mathrm{~N}$ & A \\
\hline & & Ibuprofen (IBU) & 206,28 & - & $205,0(17)$ & $161,0(7)$ & I & 0.965 & 0.188 & 0,2 & 1,0 & A & $\mathrm{N}$ \\
\hline & & Hydroxyibuprofen (OH-IBU) & 222,28 & - & $221,2(19)$ & $177,0(9)$ & $158,7(13)$ & 0.994 & 0.103 & 0,8 & 2,0 & A & $\mathrm{N}$ \\
\hline & & Ketoprofen (KETO) & 254,28 & + & $255,0(29)$ & $209,0(12)$ & $105,0(22)$ & 0.989 & 0.085 & 0,3 & 1,0 & A & A \\
\hline & & Salicylic acid (SCA) & 138,12 & - & $137,0(30)$ & $92,6(14)$ & $64,7(28)$ & 0.984 & 0.100 & 9,1 & 24,0 & A & A \\
\hline \multirow{3}{*}{\multicolumn{2}{|c|}{ Misc. }} & Acetaminophen (PARA) & 151,16 & + & $152,0(25)$ & $110,0(15)$ & $90,0(10)$ & 0.986 & 0.094 & 1,3 & 4,0 & $\mathrm{~N}+\mathrm{A}$ & A \\
\hline & & Caffeine (CAF) & 194,19 & + & $195,1(37)$ & $137,7(18)$ & $109,7(22)$ & 0.987 & 0.129 & 1,8 & 3,0 & $\mathrm{~N}+\mathrm{A}$ & A \\
\hline & & Hydrochlorothiazide (HCTZ) & 297,74 & - & $296,2(42)$ & $77,6(28)$ & $204,8(22)$ & 0.981 & 0.170 & 0,1 & 1,0 & A & $\mathrm{N}$ \\
\hline \multirow{4}{*}{\multicolumn{2}{|c|}{ Hormones }} & Ethinylestradiol (EE) & 296,40 & - & $295,2(54)$ & $144,9(40)$ & $183,0(35)$ & 0.873 & 0.406 & 2,8 & 8,0 & A & $\mathrm{N}$ \\
\hline & & $17 \beta$-Estradiol $(\beta E)$ & 272,38 & - & $271,1(50)$ & $145,0(38)$ & $183,0(41)$ & 0.741 & 0.611 & 0,4 & 1,0 & A & $\mathrm{N}$ \\
\hline & & Estrone (EO) & 270,37 & - & $269,1(53)$ & $145,0(35)$ & $183,0(36)$ & 0.875 & 0.393 & 0,5 & 1,0 & A & $\mathrm{N}$ \\
\hline & & Progesterone (PGT) & 314,46 & + & $315,2(32)$ & $97,0(24)$ & $109,0(26)$ & 0.992 & 0.097 & 0,2 & 1,0 & $\mathrm{~N}$ & A \\
\hline \multirow{3}{*}{\multicolumn{2}{|c|}{ IS }} & Ketoprofen-d3 (KETO-d3) & 257,30 & + & $258,4(25)$ & $212,0(15)$ & $179,8(23)$ & & & & & $\mathrm{N}+\mathrm{A}$ & A \\
\hline & & Caffeine- ${ }^{13} \mathrm{C}_{3}(\mathrm{CAF}-13 \mathrm{C} 3)$ & 195,19 & + & $198,2(35)$ & $139,7(20)$ & $111,7(22)$ & & & & & I & A \\
\hline & & Ibuprofene-d $\mathrm{d}_{3}$ (IBU-d3) & 209,30 & - & 208,2 (18) & $163,9(7)$ & I & & & & & l & $\mathrm{N}$ \\
\hline
\end{tabular}

${ }^{\mathrm{a}}$ Cone Voltage in volt; ${ }^{\mathrm{b}}$ Collision energy in volt; ${ }^{\mathrm{c}} \mathrm{SPE}$ extraction at $\mathrm{pH}=2$, ${ }^{\mathrm{d}} \mathrm{SPE}$ extraction at $\mathrm{pH}=7$; ${ }^{\mathrm{e}}$ Mean value of the 2 methods. ${ }^{*}$ molecule whose molecular weight of the commercial product purchased does not correspond to the molecular weight of the active compound (i.e. amlodipine besylate $-\mathrm{MW}=567.05$ versus amlodipine $-\mathrm{MW}=408.87$ ) 
a)

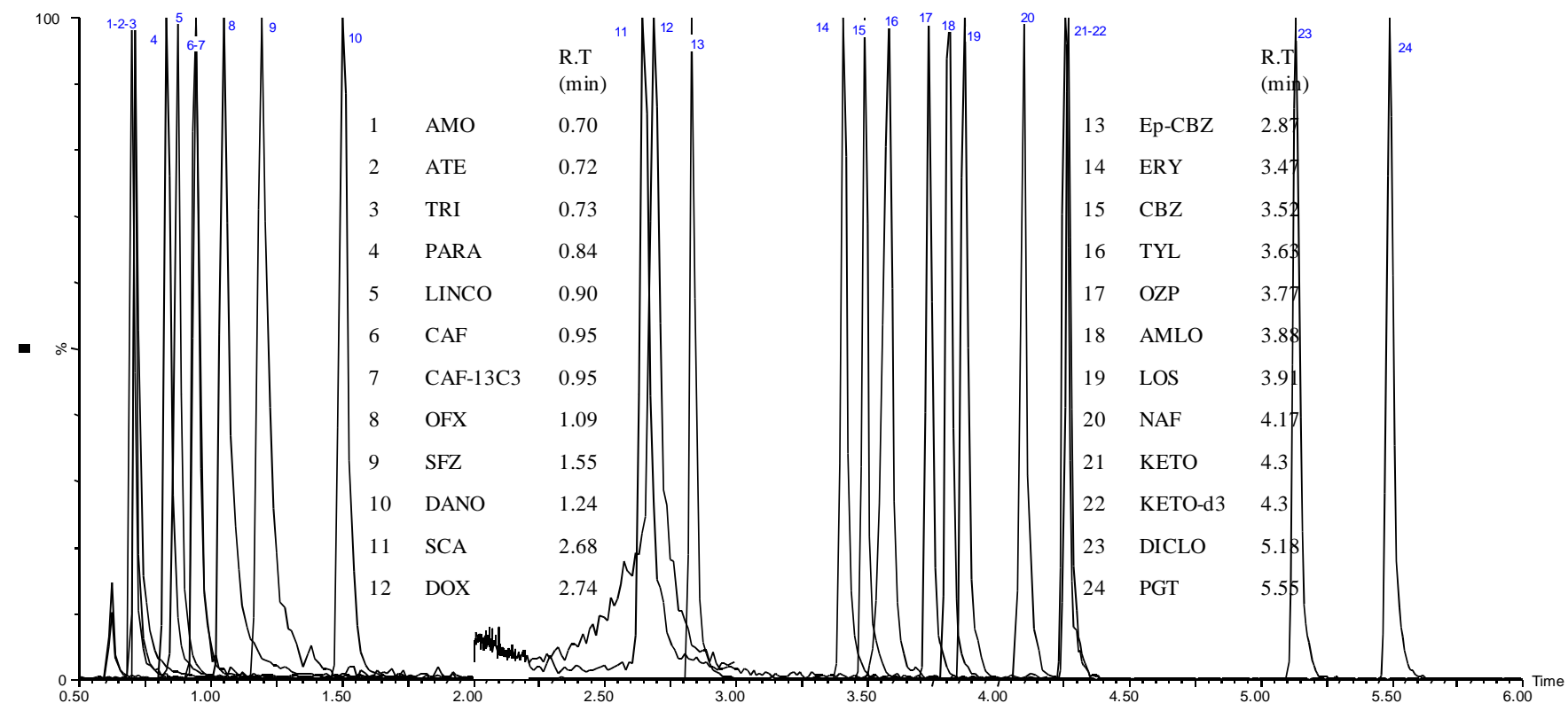

b)

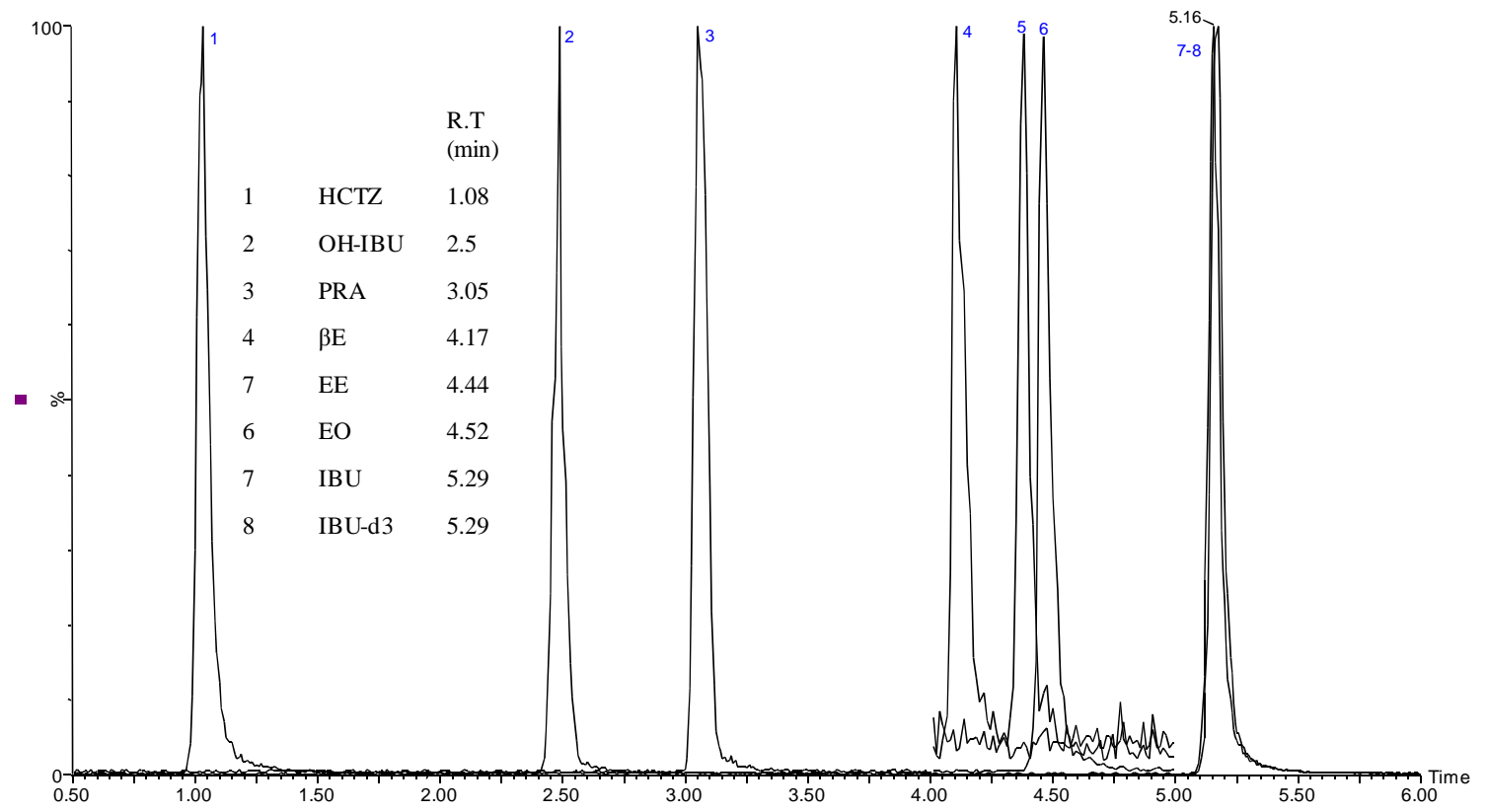

Figure 1. Example of chromatogram obtained with a standard mix solution at $100 \mu \mathrm{g} \mathrm{L}^{-1}$. Chromatograms obtained with (a) addition of $0.1 \%$ formic acid and (b) without acidification. 


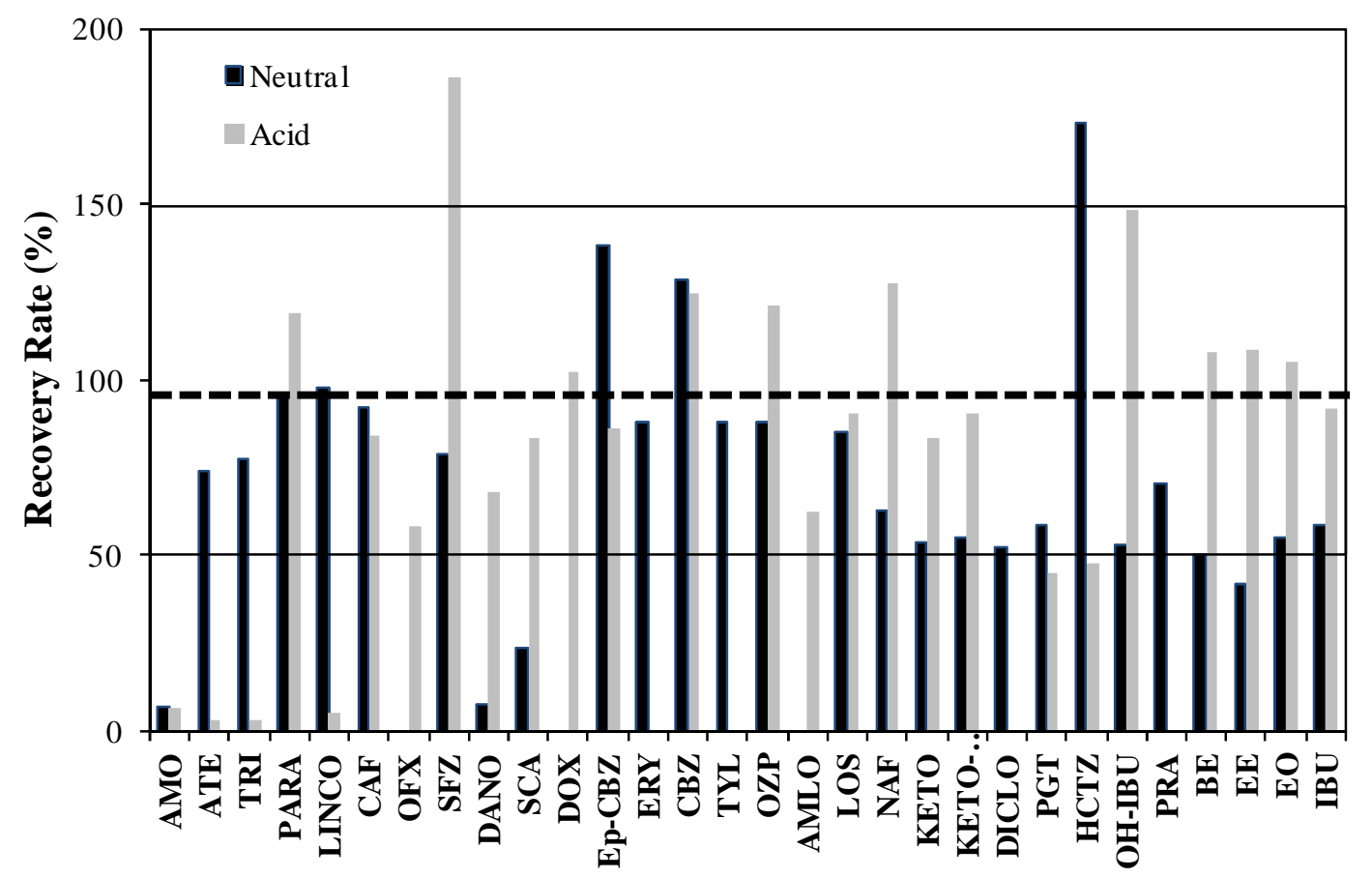

Figure 2. Effect of $\mathrm{pH}$ during SPE extraction on the recovery rate in pure water. [Analyte] $=100 \mathrm{ng} \mathrm{L}^{-1} ;$ concentration factor $=1000$. 


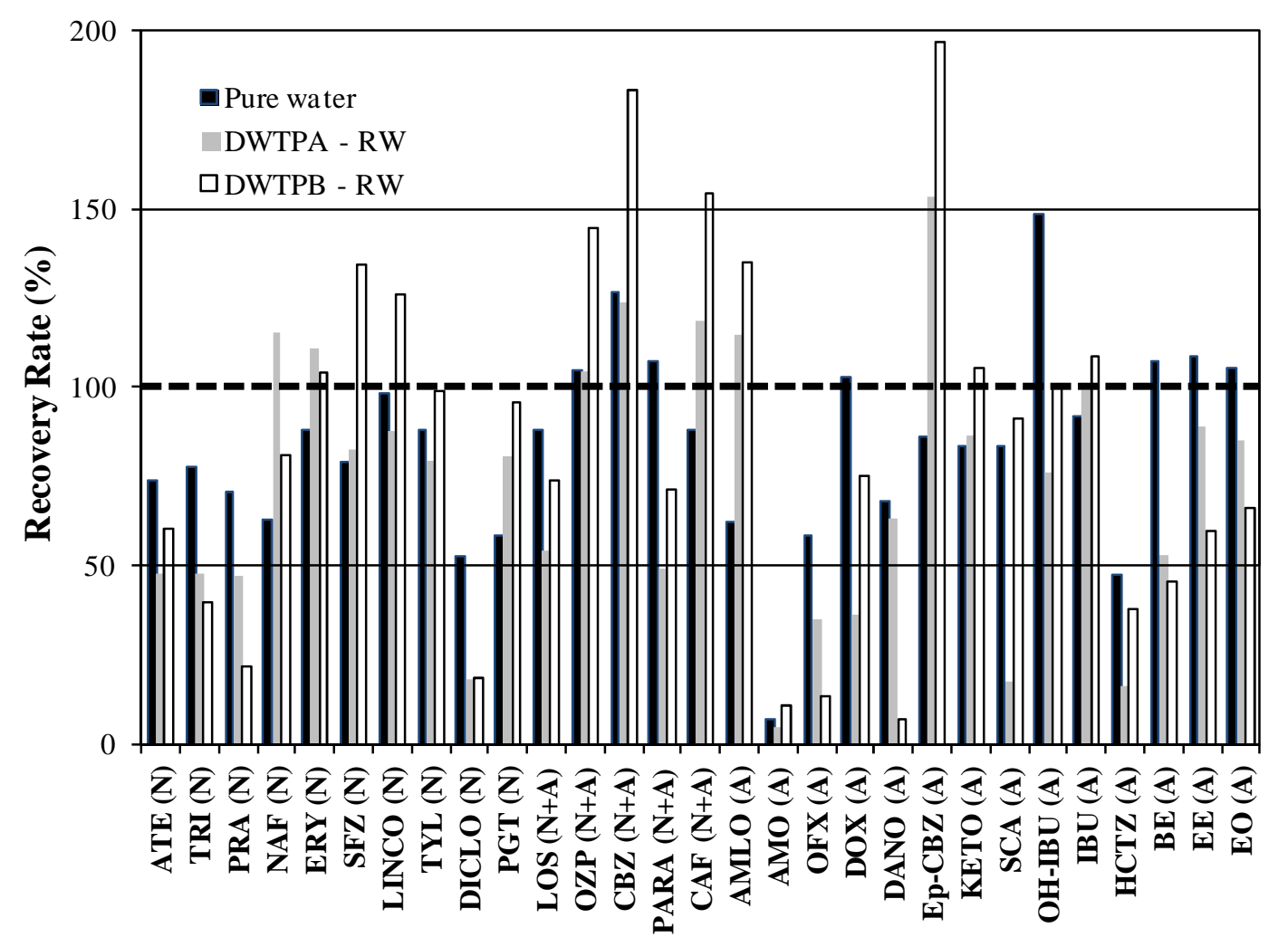

Figure 3. Effect of water quality on the recovery rate. [Analyte] $=100 \mathrm{ng} \mathrm{L}^{-1}$; concentration factor $=1000$; letters in parentheses refer to the SPE mode i.e. Acid and/or Neutral conditions. 
a/

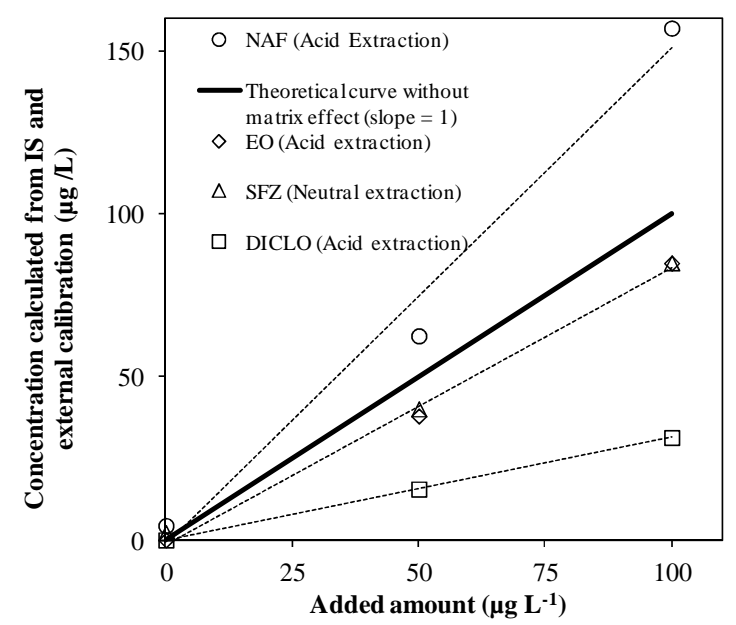

b/

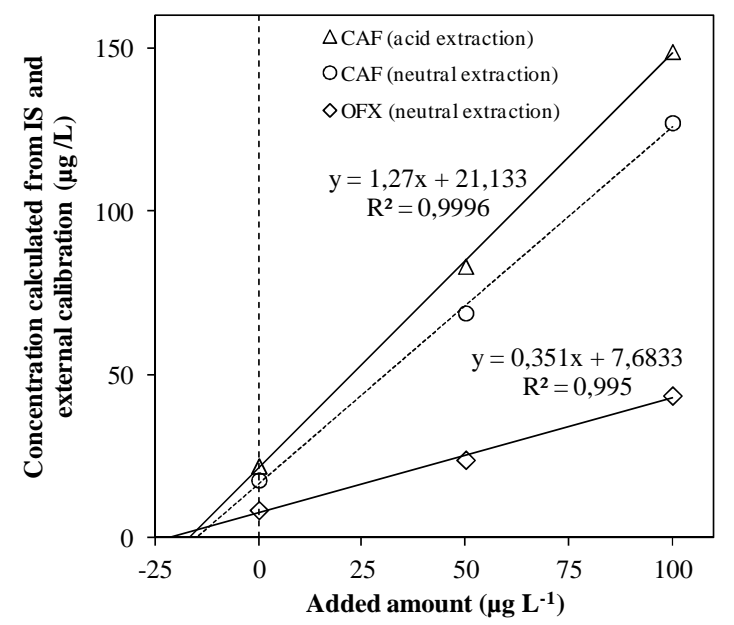

Figure 4. Comparison of concentrations determined by external calibration with internal standard correction and standard addition method. Example of compounds (a) not detected and (b) detected in DWTP A-RW. 


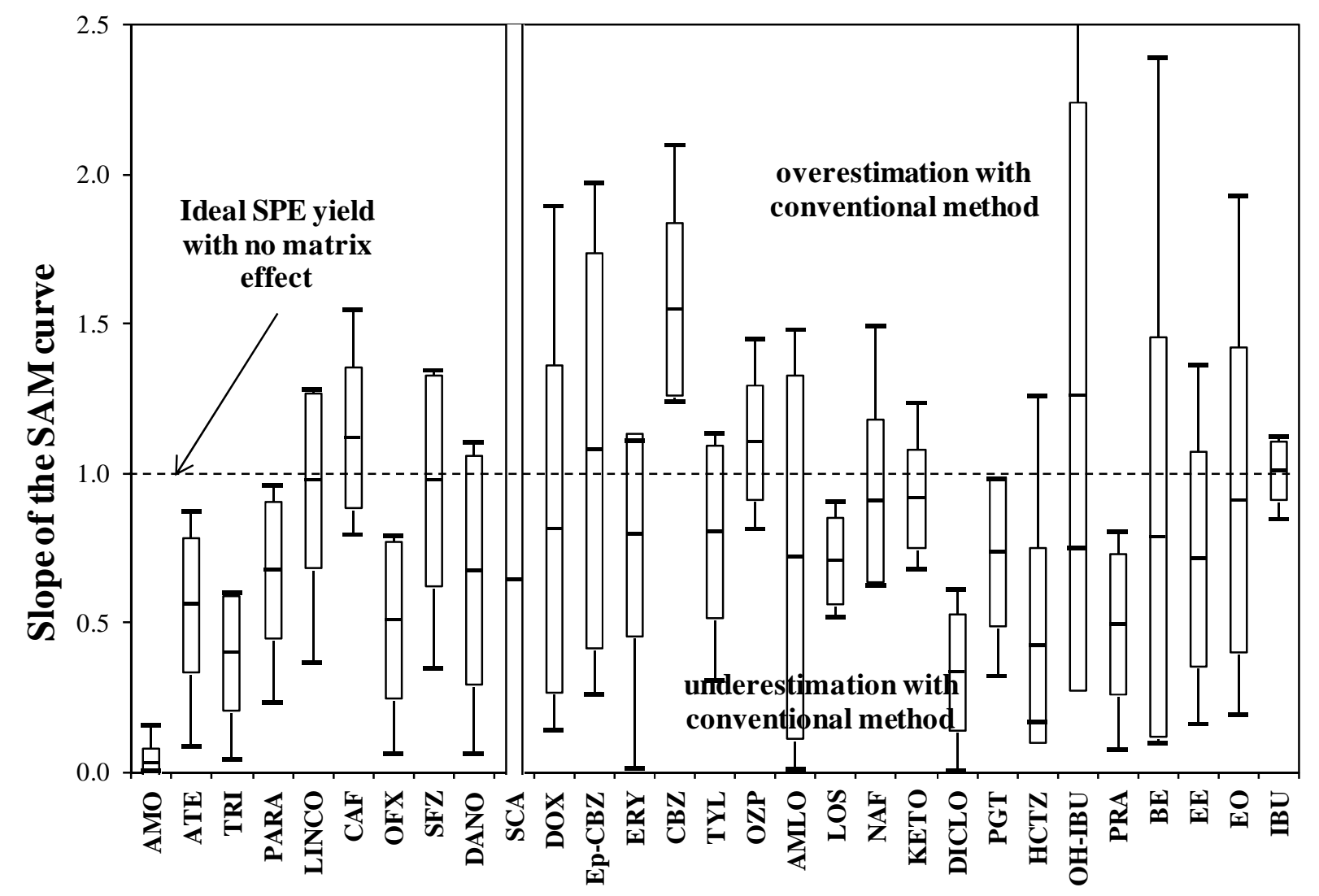

Figure 5. Overall evaluation of the matrix effect in multiresidue analysis of pharmaceutical compounds in surface and drinking water. 
a/

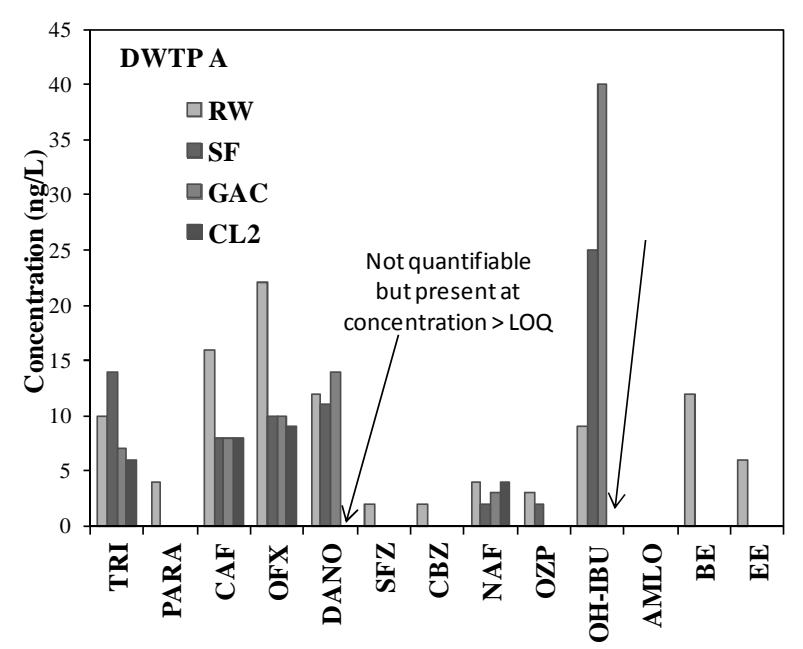

c/

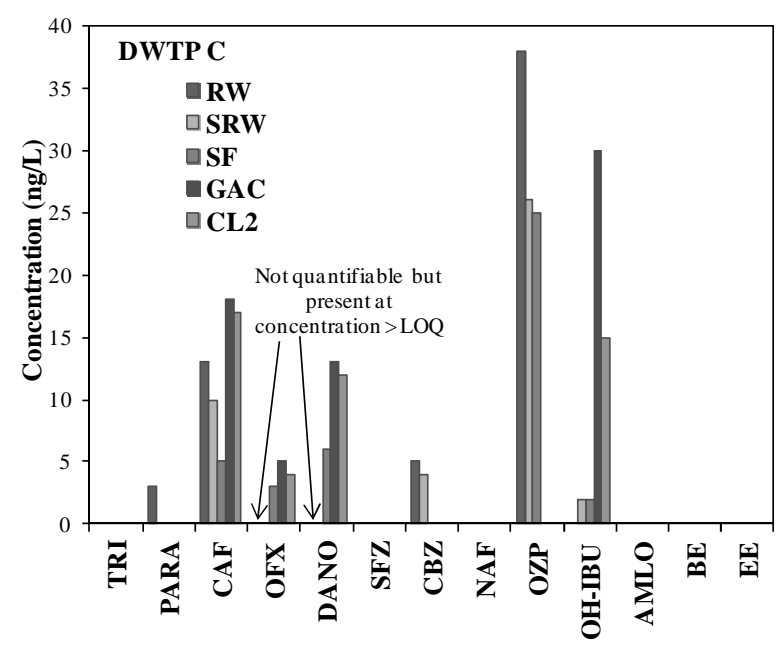

b/

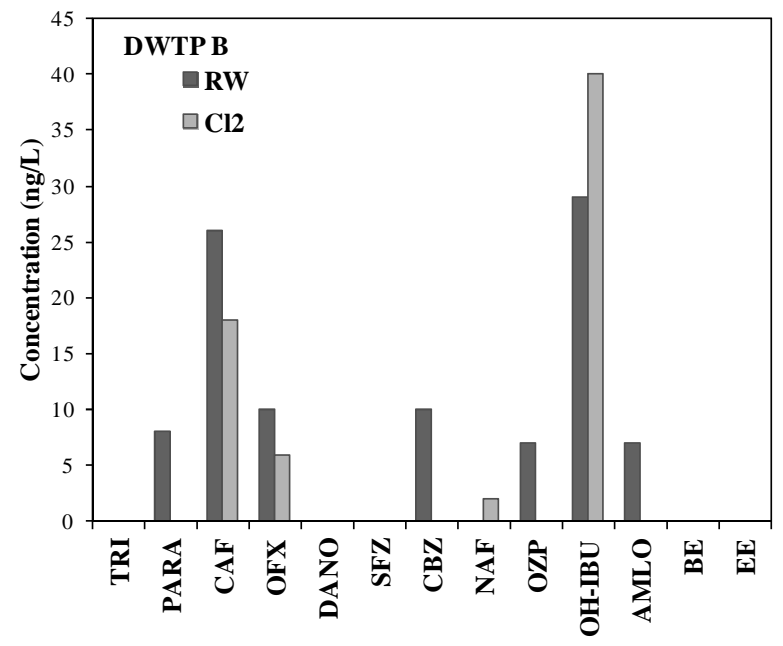

d/

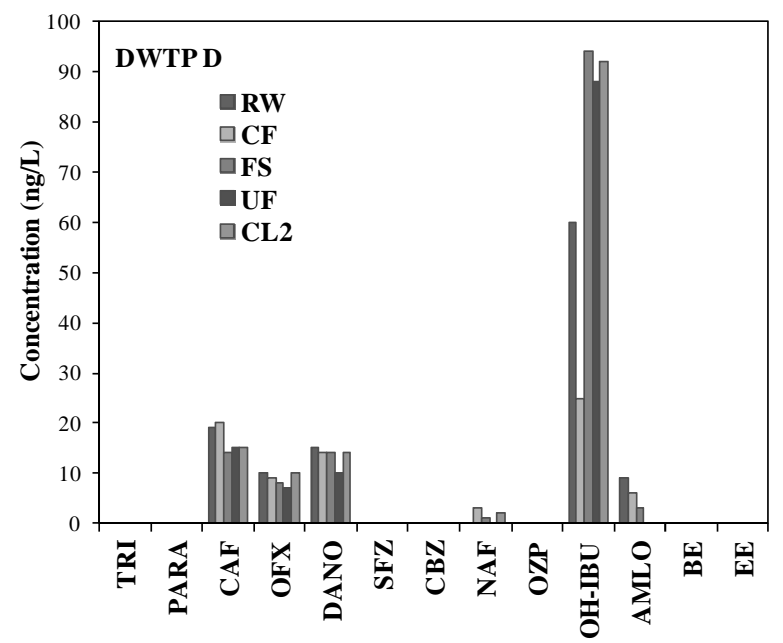

Figure 6. Fate and occurrence of pharmaceutical compounds at different stages of the drinking water process. Raw Water (RW), Stored Raw Water (SRW), Coagulation-Flocculation (CF), Sand Filtration (SF), Granular Activated Carbon (GAC) and Chlorination (CL2). DWTP A and B include an ozonation step before GAC filtration; DWTP B and D include a powder activated carbon reactor in the clarification step and a membrane ultra-filtration (UF) as a polishing treatment before chlorination. 